to expect a monthly prescription in excess of $£ 100$ ? In many of these situations the general practitioner would find himself in the position of having to choose between the care of his patients and being able to retain his legitimate income for his own and his family's use.

Too heavy a burden of sanctions must only act to increase the internal conflict that a practitioner accepts in undertaking to look after an NHS list of patients. This must lead to an attrition of good service and to bad feelings. This, I would predict, would be soon discernible from the retirement, emigration, and suicide rates of general practitioners. The very complexity of the pool system makes it difficult to reward the careful rather than the lazy doctor. Simplistic attempts to use financia incentives within that system can easily have very different effect from what was intended.

\section{A R DEwsBury}

\section{Birmingham}

Clinical Practice in its Economic Context, ed C I
Philips and J N Wolfe. London, Pitman, 1977.

\section{A tennis elbow support}

SIR,-I was interested to read the letter by Mr S C Chen (1 October, p 894) on the tennis elbow support. His preliminary results are impressive, but I would like to point out that an almost identical support has been described elsewhere, ${ }^{1}$ with similar encouraging results.

ANTHONY J RICHARDS

Department of Rheumatology,

Worthing Hospital,

Sussex

'Froimson, A I, fournal of Bone and foint Surgery,
1971, 53-A, 183.

\section{Bell's palsy and herpes simplex}

SIR,-Dr P Grout (24 September, p 829) describes a patient who had facial nerve palsy and stomatitis. It is postulated that the motor nerve palsy was due to herpes simplex virus. The evidence for this is quite inadequate. There is no substantive evidence that the stomatitis was due to herpes simplex, and only positive cultures could have proved that. W are told that there were "very high antibody titres to HSV and varicella-zoster (V-Z)" but we are not told what the titres were.

Dr F O MacCallum and I investigated many patients with Bell's palsy, but we never found any evidence that it was due to herpes simplex virus. This does not mean to say that it could not happen. Facial palsy certainly can be part of the picture of herpes simplex virus encephalitis. Stomatitis in encephalitis must be extremely rare, as it is practically never possible to recover the virus from sites outside the central nervous system. On the other hand facial palsy is perhaps the commonest form of $\mathrm{V}-\mathrm{Z}$ motor nerve involvement, alone or in association with sensory zoster. We are told that there were paraesthesiae in the area of the Vth nerve. As mentioned above, we were not told what the titre of antibody to $\mathrm{V}-\mathrm{Z}$ was, but I would submit that it is far more likely that Dr Grout's patient's motor palsy of the facial nerve was due to $\mathrm{V}-\mathrm{Z}$ virus than to herpes simplex virus. This does not preclude the possibility that the patient also had herpes simplex stomatitis, but without paired sera or positive cultures we shall never know. We were not told if the lesions were unilateral; if they were it is possible that the lesions in the mouth could have been due to zoster of the maxillary and mandibular divisions of the trigeminal nerve.

BENT JUEL-JENSEN

Radcliffe Infirmary,

Oxford

\section{Questionnaires and abuse of privacy}

SIR,-A short time ago I received a letter and questionnaire from the Medical Care Research Unit, Department of Community Medicine, University of Sheffield Medical School. The letter explained that research was being done into the problems that women face in pursuing their careers. On turning to the questionnaire I read the questions with growing disbelief. Not only was I expected to identify myself and every detail of my career completely, I was also expected to identify my parents and their occupations, and details of my husband's career if he happened to be a medical doctor.

How dare anyone under the excuse of research make such an invasion of one's privacy! Surely the answers to the problems (if any) of women in medicine can be obtained by other questions or methods. I have protested by letter to the person who sent out the questionnaire. I hope that all the other women doctors who have received such requests have either ignored them or, better still, protested as I have done. There are too frequently such blatant abuses of privacy at the present time.

Fleetwood, Lancs

Aline Sullivan

\section{Vitamin $B_{12}$ deficiency in a child}

SIR,-I was interested to read of the case of vitamin $\mathrm{B}_{1,2}$ deficiency in a child described by Dr D Attock and his colleagues (24 September, p 807). I find it surprising that a jejuna biopsy was not performed since $\mathrm{B}_{12}$ deficiency occurs commonly in coeliac disease. ${ }^{1}$ Lack of steatorrhoea," normal small-bowel radiology, and normal serum levels of folate, calcium phosphate, magnesium, and vitamin A do not exclude the diagnosis of coeliac disease. ${ }^{4}$

Using a paediatric small-intestinal biopsy capsule jejunal biopsy is a safe procedure and is not distressing to children when performed with a suitable introducer and using intravenous diazepam and metoclopramide. Indeed, by screening the position of the capsule with an image intensifier jejunal biopsy can often be performed within 5-10 minutes. It seems a pity not at least to exclude the diagnosis of coeliac disease in patients with malabsorption of $B_{1 .}$ since the condition can be readily treated with a gluten-free diet and the longterm complications of the undiagnosed disease avoided.

General Hospital,

R FERGUSON

General Hospita
Nottingham

'Hoffbrand, A V, in Clinics in Gastroenterology: Coeliac Disease, ed W T Coc

McNeish, A S, and Anderson, C M, in Clinics in Gastroenterology: Coeliac Disease, ed W T Cook and P Asquith, p 131. London, Saunders, 1974. ${ }^{3}$ Burrows, F G O, and Toye, D K M, in Clinics in Gastroenterology: Coeliac Disease, ed W T Cooke and $P$ Asquith, $p 104$. London, Saunders, 1974.

Ferguson, R, MD Thesis, University of Birmingham
Mobilisation after myocardial infarction

SIR,-Your leading article on this subject (10 September, p 651) states that the benefit of "a formal programme of physical training in a physiotherapy department or gymnasium" should be set against "the expense and time, the high drop-out rate, and the uncertainty that the long-term prognosis is improved."

This hospital has been offering a physical training programme to selected patients after myocardial infarction over the past seven years and the only expense incurred is the salary of a part-time physiotherapist, the medical staff being on call to the coronary care unit. ${ }^{1}$ The patients and their wives have been enthusiastic about the service and feel that it has improved their morale, physical fitness, and capacity both to work and to follow leisure pursuits.

We feel that there is no reason why a district hospital with coronary care responsibility should not offer this valuable and economic service.

D MCC BOYLE

J M BARBER

PATRICIA MCCOY

Ulster Hospital,

Belfast

Singh, N S, et al, fournal of the Irish Medical Associa-

Immunological deficiency, cancer, and prostaglandins

SIR,-Your leading article (10 September, p 654) expressed the hope that fundamental research may one day enable some form of biological engineering to correct the fault in congenital immunodeficiency disease. We suggest that in one form of immunodeficiency disease such "engineering" has been successfully used since 1953. The failure of research workers to recognise this is an interesting example of the danger of specialisation.

Acrodermatitis enteropathica (AE) is a congenital disease which presents soon after birth with severe acral dermatitis, total alopecia, and gastrointestinal disturbances. The skin disorder usually ensures that affected infants are referred to a dermatologist, who recognises $\mathrm{AE}$ and prescribes dihydroxyiodoquin, penicillamine, or zinc. Dihydroxyiodoquin was empirically found successful in $1953,{ }^{1}$ while the use of penicillamine was reported in 1963. More recently AE was found to be associated with zinc deficiency and zinc seems to produce a complete symptomatic cure. ${ }^{3+}$ Patients with $\mathrm{AE}$ have therefore no reason to be seen by specialists in immunodeficiency disease.

It is only on reading papers written by those who attempted to treat the disease before 1953 or who have had experience of a patient with AE which was not diagnosed as such until a late stage that the connection between $\mathrm{AE}$ and immunodeficiency can be appreciated. Untreated $\mathrm{AE}$ is associated with total or neartotal absence of the thymus, hypotrophic or absent tonsils, Peyer's patches, and peripheral lymph nodes, and evidence of both $\mathrm{T}$ and $\mathrm{B}$ lymphocyte deficiency." "There are multiple infections difficult or impossible to treat with antibiotics. Candida and pseudomonas are common infecting organisms and in several cases which came to necropsy the described lung changes were consistent with Pneumocystis carinii infection. 711

It seems to us therefore that $\mathrm{AE}$ is a form of immunodeficiency disease which, with its 